\title{
Effect of Nozzle Velocity, Nozzle Angle and Standoff Distance on the Dredge Output during Placer Mining
}

\author{
P K Sen ${ }^{1}$, LG Das ${ }^{1}$, B Haldar ${ }^{2}$, M Sundarrajan ${ }^{3}$ and P K Chatterjee ${ }^{1 *}$ \\ ${ }^{I}$ CSIR Central Mechanical Engineering Research Institute, Durgapur - 713209, India \\ ${ }^{2}$ National Institute of Technology, Durgapur - 713209, India \\ ${ }^{3}$ CSIR Central Institute of Mines and Fuel Research, Dhanbad - 826015, India
}

\begin{abstract}
Placers are deposits of detrital materials in which valuable minerals have been concentrated by the oceanographic processes of waves and currents. These minerals are important economic source as they are useful in many industries for various purposes. India has rich placer mineral deposits at many locations along the long coastline of more than $6000 \mathrm{~km}$. Contrary to the deposits of other countries, Indian deposits of placer are multi mineral in nature consisting of ilmenite, rutile, leucoxene, zircon, monazite, sillimanite garnet, kyanite, magnetite, casseterite, etc. In this study a pilot mining system of capacity 50 tons per hour operating at a maximum depth of 10 meters has been designed and developed to investigate the effect of different parameters, e.g., water jet velocity, distance from the nozzle tip to the mineral bed, time of operation, on the concentration of mineral sand in the discharge water. The solid concentration obtained is $10.6 \%(v / v)$ for a water jet velocity of $20 \mathrm{~m} / \mathrm{s}$. It has been observed that the solid concentration in the delivery line increases upto $14.8 \%$ with the change in the distance between the nozzle tip and the mineral bed.

Keywords: Placer mining; dredge output; mineral sand; translation velocity; soil shear strength
\end{abstract}

\section{Introduction:}

Placers are deposits of detrital materials in which valuable minerals have been concentrated by the oceanographic processes of waves and currents[1]. These minerals are important economic source as they are useful in many industries for various purposes. India has rich placer mineral deposits at many locations along the long coastline of more than $6000 \mathrm{~km}$. Contrary to the deposits of other countries, Indian deposits of placer are multi mineral in nature consisting of ilmenite, rutile, leucoxene, zircon, monazite, sillimanite garnet, kyanite, magnetite, casseterite, etc. Ilmenite [2] reserves of India account for nearly $46 \%$ of the world's reserves. Also about $10 \%$ rutile and $14 \%$ zircon of the total world resources are deposited in India.

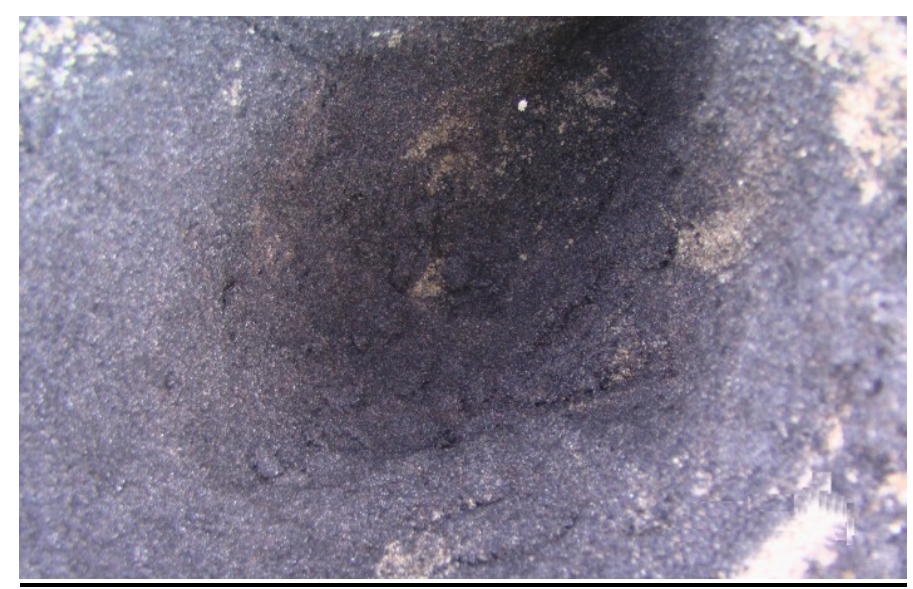

Fig. 1 Placer sand deposit onshore at Ratnagiri Bay, India

Moreover, the weight percentage of heavies in beach sand is much higher than in other countries, making the deposits economical for exploitation. The multimineral assemblages of the Indian coastal sands can open up wide spectrum of industrial applications in many fields ranging from the aerospace industry to ceramic and paint industries. It is therefore very important that the own placer mineral resources $[3,4]$ are utilized suitably to increase the placer minerals resource of the country. Since this is comparatively a new field in India, this needs to have consistent and comprehensive development planning in all dimensions viz. exploration, mining, processing, value addition and law making. This research work has been tuned to focus mainly the four E's : Exploration, Exploitation, Enrichment and Environment of placer minerals. 
The main objective was to develop an indigenous mining technology for offshore coastal placer mining at a shallow depth. The major activities are: i) Design and development of a pilot mining system of capacity 50 tons per hour operating at a maximum depth of 10 meters.

ii) Experimentation and data generation for the design and development of a commercial coastal placer mining system for maximum mineral output.

\section{Materials And Methods:}

A placer mining system for offshore pilot mining of placer deposits has been designed and developed. The salient feature of this system is to loosen the sand on the seabed by impinging high pressure water jet and to pump out the sand-water slurry by a submersible slurry pump. The slurry is collected into a hopper barge. Solid placer sands are settled down and the water is sent back to the sea. The experiments were carried out in the geographical location of the mining site of $17^{\circ} 2{ }^{\prime} 30^{\prime \prime}$ to $17^{\circ} 4^{\prime} 30^{\prime \prime}$ latitude north and $73^{\circ} 16^{\prime} 55^{\prime \prime}$ to $73^{\circ} 17^{\prime} 20^{\prime \prime}$ longitude east in the Arabian sea near Kalvadevi bay of Ratanagiri District of Maharastra, India. The minerals are collected from the sea bed with help of a dredge head Figure $2 \& 3$ and a collection pipe to suck the mineral water slurry from the sea bed.

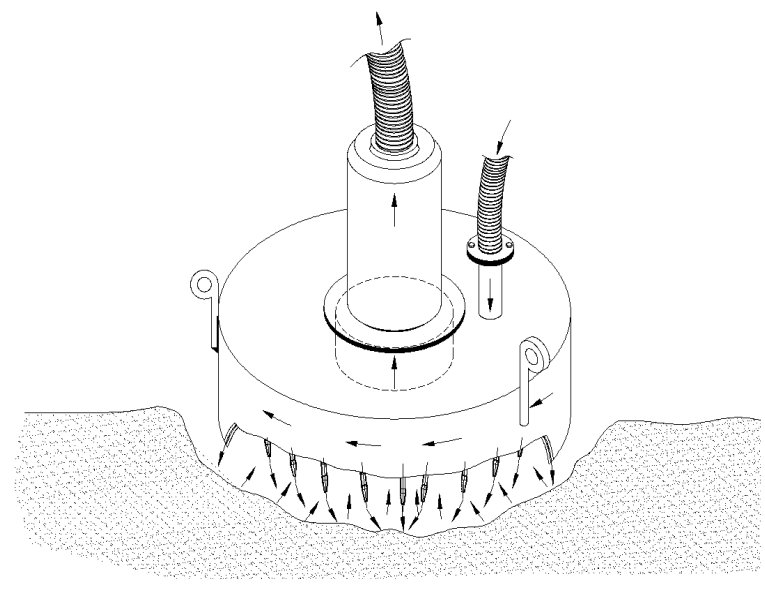

Fig. 2 The schematic diagram of the dredge head

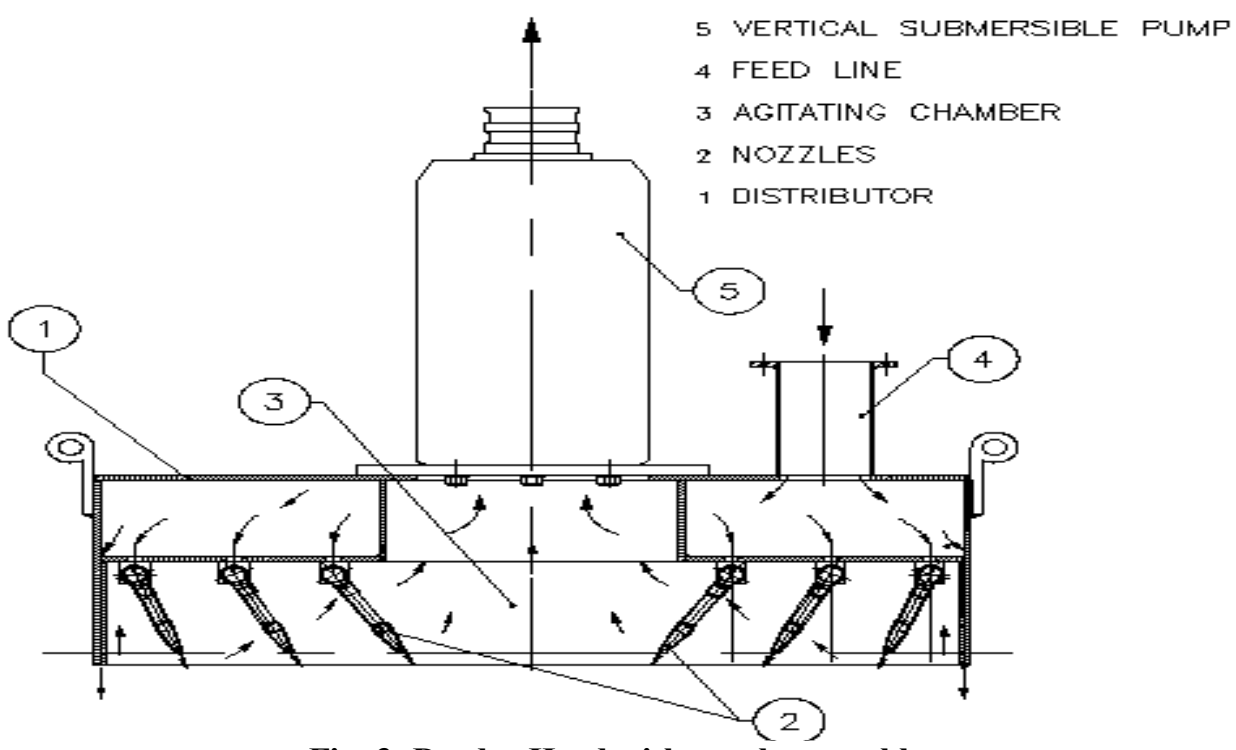

Fig. 3: Dredge Head with nozzle assembly

Water from heavy-duty centrifugal pump enters into the chamber of dredge head and leaves through the nozzles with high velocity. The nozzles are fitted to the dredge head with banjo joints so that the angle of the nozzles can be changed for maximum concentration slurry. The high-pressurized water jet from the nozzles impinges on the seabed. By this process heavy mineral sand is loosened and it forms sand-water slurry inside 
the dredge head. During the pilot mining operations all the equipments were installed on an anchored flat top barge of $35 \mathrm{~m}$ length, $11 \mathrm{~m}$ breadth and $2.51 \mathrm{~m}$ depth and of 500 ton load carrying capacity. A crane of $12.5 \mathrm{~m}$ boom length and load lifting capacity of 30 ton for equipment handling and a Diesel Generator Set of $320 \mathrm{kVA}$ for power supply to equipments were installed on the barge. The entire assembly is shown in Figure 4. The dredged material was discharged to a nearby anchored hopper barge of 300 ton capacity. A tug of 400 BHP was used to move the barges at various locations on the sea. The horizontal centrifugal pump for sea water supply to the dredge head and vertical submersible slurry pump for discharging sand-water suspension from dredge head to the hopper barge $[5,6]$ were also installed.

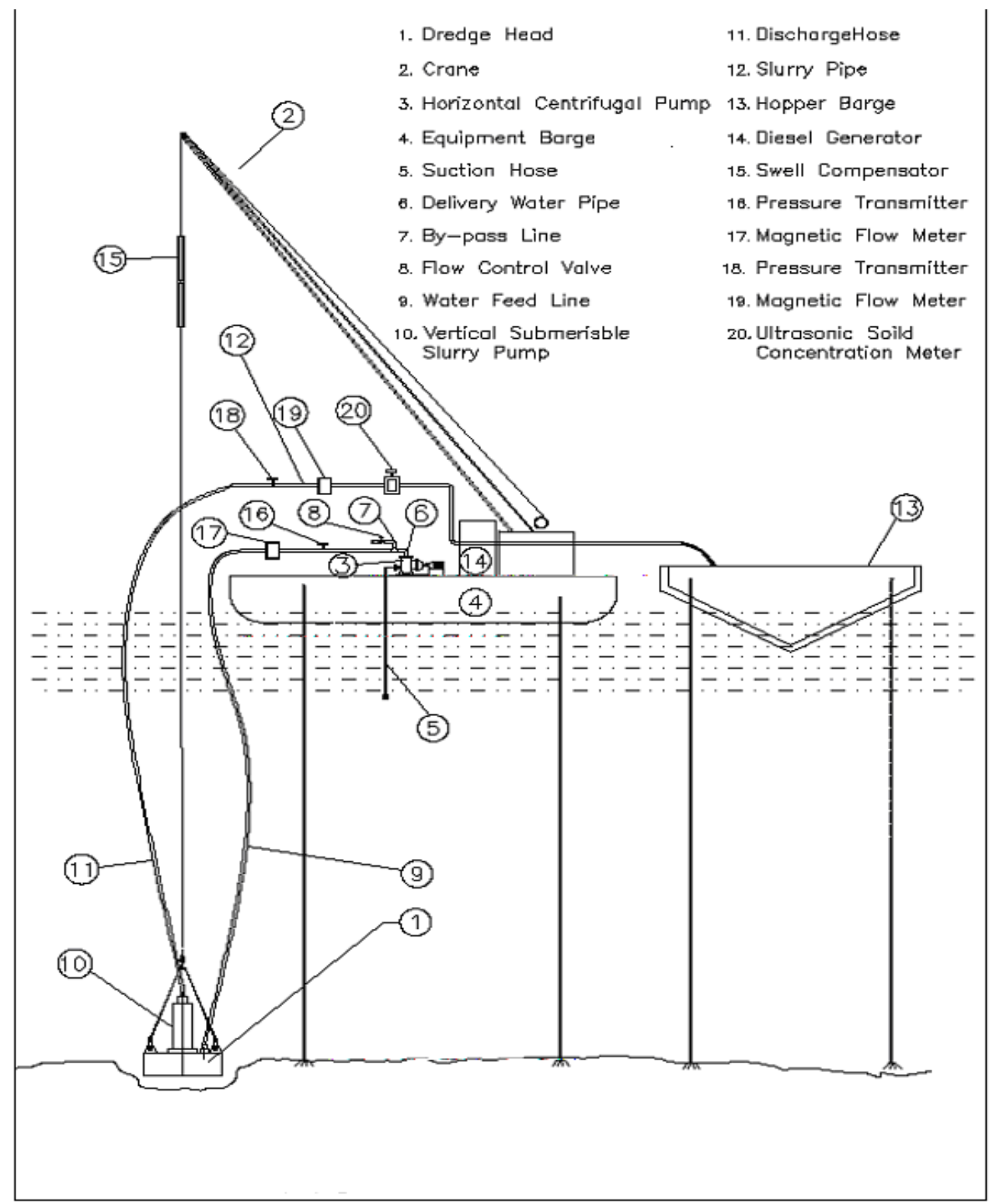

Fig. 4 The Pilot set up for offshore placer mining

III. Results And Discussion

Different variable parameters of dredging by water jets eg. nozzle exit velocity, height of the nozzle tips from sand bed, water depth and diffusivity of water jets in water were studied during the pilot mining operations.

It was observed that the depth of cut of the soil increases with increase of nozzle exit velocity and it decreases with the increase of soil shear strength. The water jets did not cut the soil bed in regular manner with straight walls. In all the cases it was highly irregular resulting formation of sand and water slurry. The variation of solid concentration of dredge output with the jet velocity is given in Fig.5. 


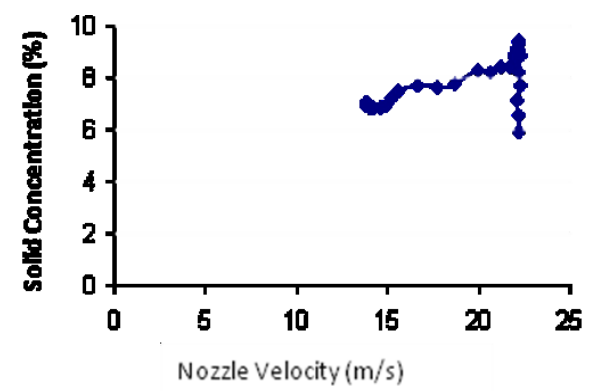

Fig.5 Effect of nozzle velocity on the solid mining

It has been also observed that dredge output decrease with the increase of water level. Increasing the standoff distance (between nozzle tips and sandbed surface), depth of cut decreases but width of the cut increase because of diffusion of the immersed water jets. It has been found out in the model test that solid concentration is maximized at standoff distance between 40 to $50 \mathrm{~mm}$. A suitable standoff distance depending on the soil characteristic gives the best dredge output. Effect of the Standoff distance on the dredge output has been plotted and given in Fig. 6.

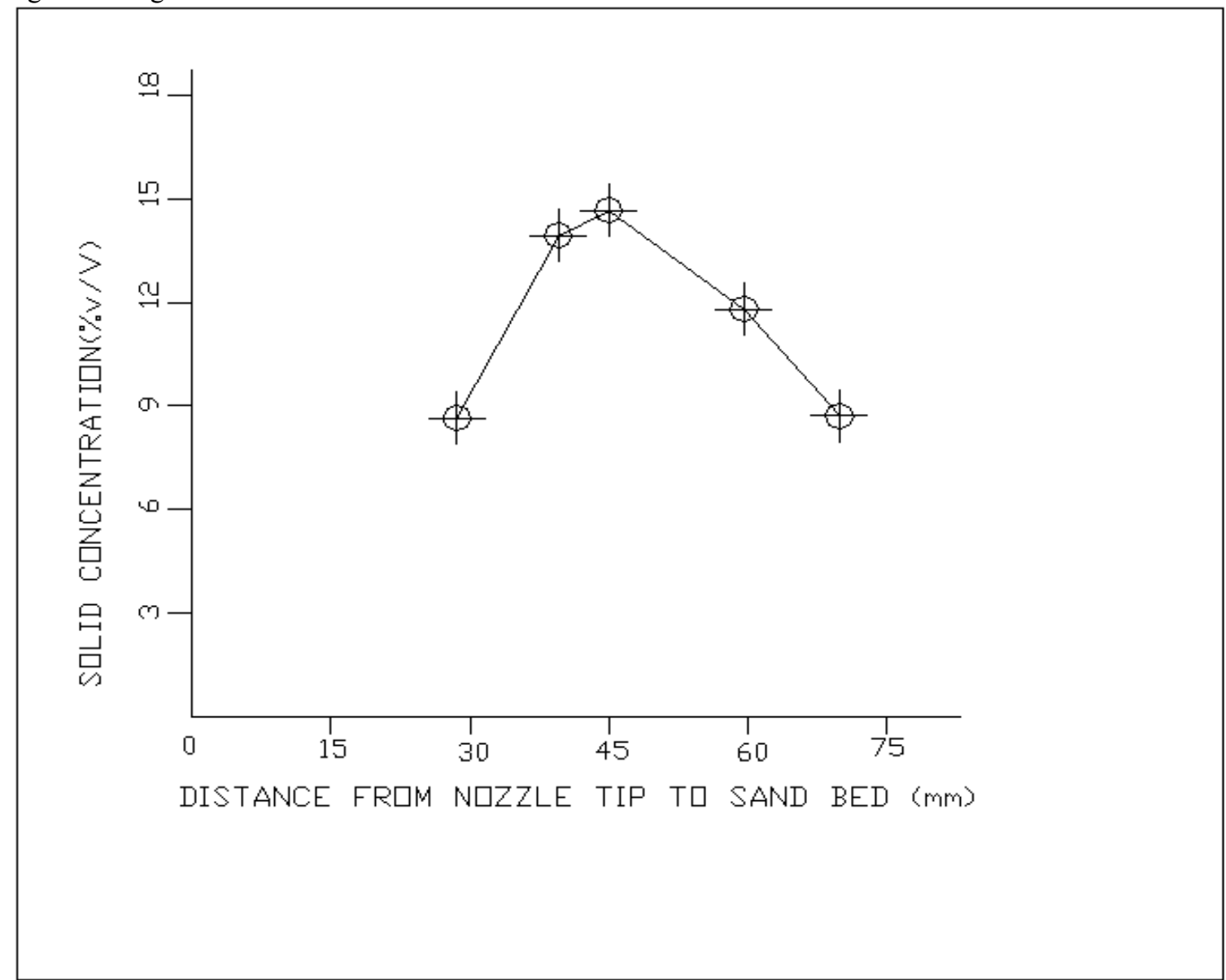

Fig. 6 Effect of Distance Between Nozzle Tip and Sand bed on Solid Concentration of Dredge Output

Dredge output also depends on the direction of nozzle exit velocity. It has been observed that nozzle exit velocity with angle $30^{\circ}$ to $45^{\circ}$ with the horizontal plane gives the optimum dredge output. The effect of nozzle angle on the dredge output is shown in Figure 7 and 8. 


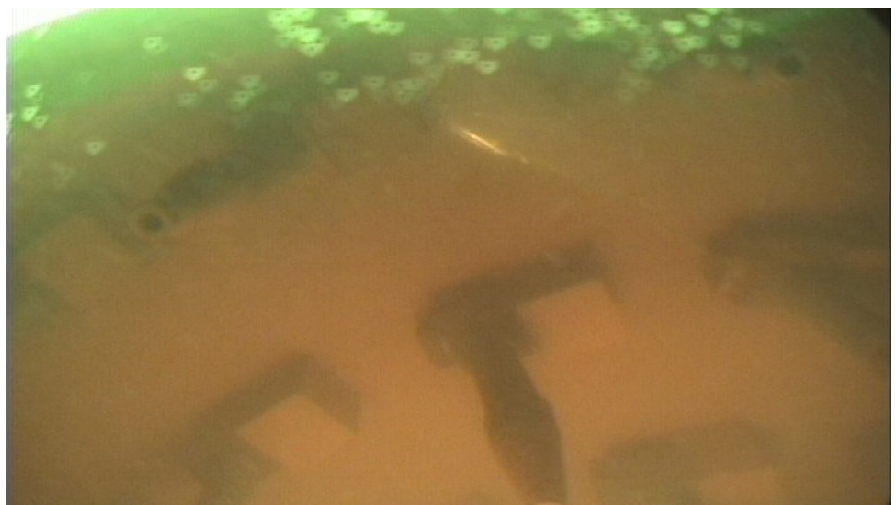

Fig. 7 Underwater View of Dredge Head's Nozzle

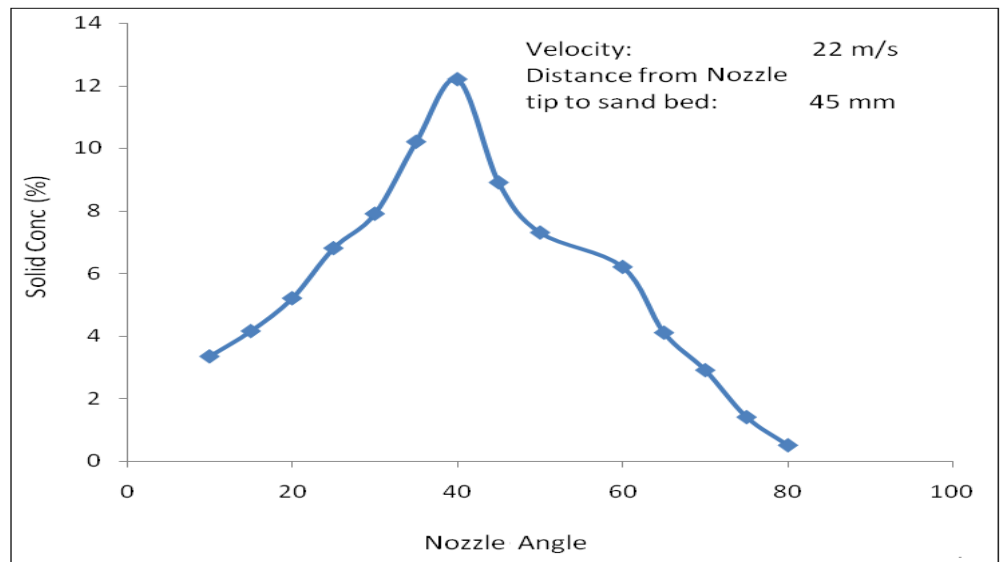

Fig. 8 The effect of nozzle angle with the dredge output

\section{Conclusion:}

The effect of different variable parameters of dredging by water jets e.g., nozzle exit velocity and height of the nozzle tips from sand bed were studied during the pilot mining operations. All the test results obtained from both the project site as well from CMERI shallow basin simulated test setup have been analyzed. It has been found that the depth of cut of the seabed increases with the increase of nozzle velocity and it decreases with the increase of soil shear strength. Although the depth of cut increases with increase of jet velocity, it was observed that dredge output decreases with increase of jet velocity after attaining the peak jet velocity. It has also been observed that dredge output decrease with the increase of water level. Increasing the stand-off distance, depth of cut decreases but width of the cut increase because of diffusion of the immersed water jets. Reducing the standoff distance of nozzle, depth of cut in the seabed increases but width of cut decreases. Also it has been found that in the seabed mining operation solid concentration is maximized at standoff distance between 40 to $50 \mathrm{~mm}$. A suitable standoff distance depending on the soil characteristics gives the best dredge output.

\section{Acknowledge:}

The authors are grateful to Director, CSIR-CMERI for his kind support and encouragement to carry out this research work.

\section{References:}

[1] Michael Silva, Placer Gold Recovery Methods, Special publication 87, California Department of Conservation Division of Mines and Geology, 1986.

[2] CALVERT, S. E. \& CRONAN, D. S. (1978). Geochemistry of oceanic ferromanganese deposits [and discussion]. Philosophical Transactions of the Royal Society of London. Series A, Mathematical and Physical Sciences, 290, 43-73, 1978

[3] BIRNEY, K., GRIFFIN, A., GWIAZDA, J., KEFAUVER, J., NAGAI, T. \& VARCHOL, D.(2006). Potential Deep-sea Mining of Seafloor Massive Sulfides: A Case Study in Papua New Guinea. University of California, Santa Barbara, USA.2006

[4] Bertram, C., Krätschell, A., O’brien, K., Brückmann, W., Proelss, A. \& Rehdanz, K., Metalliferous sediments in the Atlantis II Deep-Assessing the geological and economic resource potential and legal constraints. Resources Policy, 36, 315-329, 2011

[5] Bai, Y. (2001). Pipelines and Risers. Amsterdam: Elsevier.

[6] ALDERTON, N. \& THETHI, R., Choosing the most appropriate rigid catenary riser design for various deepwater and harsh environments. Advances in Riser Systems \& Subsea Technologies for Deepwater Euroforum. Aberdeen, 1998 